\title{
FORMAÇÃO DE PROFESSORES E PRECEPTORES NO CONTEXTO DE INOVAÇÕES CURRICULARES
}

TRAINING OF TEACHERS AND PRECEPTORS

IN THE CONTEXT OF CURRICULAR

INNOVATIONS

${ }^{1}$ Professora associada da UFRJ

${ }^{2}$ Professora associada da UFRJ

${ }^{3}$ Professora associada do IPUB-UFRJ

${ }^{4}$ Médica tutora do curso Docência na Saúde da UFRGS

${ }^{5}$ Médica tutora do curso de Formação Pedagógica de

Preceptores da UFRJ

${ }^{6}$ Médica tutora do curso de Formação

Pedagógica de

Preceptores da UFRJ

${ }^{7}$ Professora adjunta da Faculdade de Medicina da UFRJ

\section{RESUMO}

Relato da experiência sobre o desenvolvimento de curso semipresencial de aperfeiçoamento oferecido pela Universidade Federal do Rio de Janeiro, denominado: "Formação pedagógica dos formadores dos profissionais da saúde: a preceptoria dos internatos em questão". Norteado pela qualificação da formação médica e pela implementação de método ativo para formação pedagógica de formadores dos profissionais de saúde para o SUS, o curso usa a Aprendizagem Baseada em Problema ( $A B P$ ) como método, além do apoio de uma ferramenta de autoria para a parte virtual. A utilização de método ativo foi avaliada como o diferencial nesse processo de formação pedagógica, pois, segundo os participantes do curso, a busca ativa, os trabalhos em grupo e as discussões nos fóruns 
virtuais foram potencialmente motivadores para aquisição de competências necessárias para estudar e responder as questões orientadoras de aprendizagem dos quatro módulos com os quais se desenvolve o curso e para promover mudanças nas suas práticas.

Palavras-chave: Educação. Aprendizagem baseada em problema. Saúde.

\section{PONTO DE PARTIDA}

Este texto é o relato sobre a experiência de desenvolvimento de um curso semipresencial de aperfeiçoamento ofertado pela Universidade Federal do Rio de Janeiro (UFRJ), denominado: "Formação pedagógica dos formadores dos profissionais da saúde: a preceptoria dos internatos em questão".

Totalizando oito versões em 2014, realizou-se a formação pedagógica de 280 preceptores, tendo, dentre eles, um considerável número de professores e profissionais da Rede de Atenção à Saúde do Rio de Janeiro que nos procurou com interesse em repensar a própria prática docente.

A experiência com o curso iniciou-se em 2007, após aprovação de projeto no Edital 23/2006-CNPq: Formação pedagógica dos formadores dos profissionais da saúde: a preceptoria dos internatos em questão. Tínhamos como objetivos: a melhoria da formação médica por meio da capacitação pedagógica dos preceptores do internato; a implementação de método ativo 
para formação pedagógica de formadores dos profissionais de saúde para o SUS. Método esse que nos levou à constituição de uma equipe de tutoras com o seguinte perfil: seis profissionais da saúde e uma da educação estrito senso, das quais duas eram médicas anestesiologistas, mestras em educação e saúde; duas médicas ligadas à Saúde da Família, ambas professoras de Atenção Básica, uma, com mestrado, e outra, com doutorado em Saúde Coletiva; duas psicólogas, uma, doutora em Educação, e outra, em Saúde Pública, responsável pela coordenação de uma residência multiprofissional; e uma doutora em Educação que traz a experiência do movimento de formação pedagógica docente, no âmbito da reforma curricular da Faculdade de Medicina da UFRJ, especialmente no que diz respeito à revisão dos métodos de ensino e de avaliação.

É, então, essa experiência que nos autoriza a falar sobre formação de professores.

Tomamos de empréstimo o conceito de experiência trabalhado por Larrosa (2002). Segundo ele, é a experiência que provoca mudanças nas relações do homem com o meio. Propõe, então, um exercício de elaboração contínua, no qual a realidade é descrita, apreendida, interpretada e reinventada com base na experiência e nos acontecimentos cotidianos. Esse autor nos ajuda a pensar a importância das vivências no processo de ensino-aprendizagem: “A experiência é o que nos passa, o que nos acontece, o que nos toca. Não o que se passa, não o que acontece, ou o que toca" (LARROSA, 2002).

Larrosa (2002) complementa o argumento ao afirmar que o sujeito da experiência é aquele que está exposto, mostra-se vulnerável ao acontecimento, corre risco em uma dimensão 
que relaciona travessia e perigo de modo simultâneo e que, ao passar por nós, acomete-nos, forma-nos e transforma-nos, reconhecendo uma espécie de mediação entre conhecimento e vida nas experiências vividas.

O conceito de experiência exige que sejamos tocados, atravessados pelos eventos da vida, do mundo do trabalho. "Nunca se passaram tantas coisas, mas a experiência é cada vez mais rara" (LARROSA, 2002).

Nesse sentido é que a metodologia aqui proposta alinha-se ao modelo de aprendizagem sustentado pelo conhecimento que se constrói com base na experiência, em um saber que emerge do fazer.

Quanto às inovações curriculares, o que fazemos com os preceptores é usar a problematização como metodologia e a Aprendizagem Baseada em Problema $(A B P)^{1}$ como método, com o apoio de uma plataforma virtual, a Constructore, desenvolvida pelo Laboratório de Tecnologias Cognitivas (LTC)

\footnotetext{
${ }^{1}$ A Aprendizagem Baseada em Problemas (ABP) surge entre o final da década de 1960 e o início da década de 1970, nas Faculdades de Medicina da Universidade de McMaster, no Canadá, depois, na Universidade de Maastricht, na Holanda. A ABP entende o processo de aprendizagem como dinâmico e centrado na participação ativa dos estudantes. Nesse método, a aposta é que a participação ativa da aprendizagem é mais produtiva que a transferência passiva de informações do professor ao estudante. Os estudantes, assim, são chamados a problematizar, pesquisar, refletir, dar significado e entender os conteúdos trabalhados, uma vez que desenvolvem abordagens para a solução de problemas específicos em um contexto relevante à futura carreira profissional (CYRINO; TORALLES-PEREIRA, 2004).
} 
do Núcleo de Tecnologia Educacional para a Saúde (Nutes) da Universidade Federal do Rio de Janeiro. Essa ferramenta oferece a professores e alunos da UFRJ a oportunidade de desenvolverem materiais e atividades educativos semipresenciais e a distância para as ações de pesquisa, ensino e extensão. É uma ferramenta bastante amigável, com a qual desenvolvemos a parte virtual do curso.

O uso de método ativo tem se mostrado extremamente eficiente e, com algumas resistências iniciais, tem sido avaliado como o diferencial nesse processo de formação pedagógica, pois, segundo avaliação dos participantes do curso, a busca ativa, os trabalhos em grupo, as discussões nos fóruns virtuais foram situações que os tiraram da zona de conforto, tornandoos mais sensíveis e motivados para a busca de referências necessárias para estudar e responder as questões orientadoras de aprendizagem, correspondentes aos quatro módulos com os quais se desenvolve o curso, uma aquisição que, segundo eles, é levada não só para a docência mas também para a vida (RIBEIRO, 2011).

\section{CONTEXTO}

Essa experiência nasce no contexto da 3 a Conferência Nacional de Gestão do Trabalho e da Educação na Saúde (MS/Conselho Nacional de Saúde), realizada em março de 2006, na qual a Política de Educação em Saúde figura como componente estratégico da gestão do SUS, uma vez que propõe a formação e o desenvolvimento dos profissionais da saúde, preparando-os para o atendimento ético, humanizado e de qualidade, competências previstas nas Diretrizes Curriculares 
Nacionais para os cursos da área da saúde (BRASIL, 2001; BRASIL, 2014). Questões como a integralidade das ações de saúde, territorialidade, multidisciplinaridade, humanização do cuidado, saber popular, dentre outras, figuram ao lado de propostas de integração ensino/serviço, itinerário da educação profissional em saúde e qualificação para gestão, o que evidencia o caráter abrangente e complexo de toda e qualquer ação que se venha a planejar nessa área. A proposta de que os processos de mudança curricular realizados pelas escolas de graduação em saúde articulem e estabeleçam "ações cooperadas entre o SUS, as instituições de ensino (...) e os movimentos sociais (...)" (BRASIL, 2006) parece tanto ter possibilitado a execução de pesquisa e desenvolvimento em torno de temas relevantes para a sociedade, visando à mudança, quanto favorecido estágios ou programas de extensão que propiciam ao aluno participar (com supervisão docente e preceptoria médica e de outras áreas da saúde) das diferentes ações em diferentes níveis de atenção à saúde e contribuir para a otimização do atendimento à comunidade. Tudo isso ao lado das grandes mudanças que vêm acontecendo na sociedade, tais como o alargamento do tempo médio de vida, as mudanças econômicas, sociais e demográficas, a progressiva urbanização das populações e a crescente consciência das pessoas com relação aos direitos que possuem no campo da saúde, fatores que configuram exigências para se alterar a formação dos profissionais de saúde, tornando-os habilitados a trabalhar com esses problemas.

Com base nesse contexto, pensamos em ampliar o que vínhamos fazendo, desde o ano 2000, na disciplina Planejamento Curricular e de Ensino na Área da Saúde, do 
Núcleo de Tecnologia Educacional para a Saúde, obrigatória nos programas de pós-graduação em Medicina e em Odontologia da UFRJ e que destacava a importância da aquisição e da construção de conhecimentos na área da educação como instrumentos de apoio a mudanças curriculares e na prática docente.

Avaliada a experiência, na qual era usado o método de $A B P$, decidimos ampliar essa nova forma de relação mestrandoprofessor no processo de ensino-aprendizagem para as atividades de preceptoria dos internos da Faculdade de Medicina da UFRJ, majoritariamente exercidas por médicos sem qualquer formação pedagógica. E essa é a experiência que consideramos uma inovação curricular, em especial, levandose em conta o peso institucional, eminentemente tradicional, do ambiente no qual essa inovação seria implantada.

Este é o cenário que preparamos para desenvolver este texto: de um lado, a formação pedagógica de preceptores e professores; de outro, o método que usamos no processo de formação: ABP. Diante disso, o grupo de tutoras decidiu discutir, em um grupo focal, os desafios e as possibilidades da experiência, ou seja, as situações de desconforto, de desequilíbrio, de dúvidas e de suspeitas enfrentadas nos oito cursos já transcorridos, as quais consideramos como desafios; e os anúncios, as esperanças que identificamos como possibilidades de conquistas, de superação dos desafios, dentre os quais, destacamos os seguintes: o exercício do protagonismo, o compartilhamento, a governabilidade no processo de trabalho, a conquista da autonomia, a descoberta do potencial para inovar/ousar, a 
função de autoria, os encontros e desencontros nas relações pedagógicas.

\section{DESAFIOS E POSSIBILIDADES}

Um primeiro desafio é chegar ao professor, ao médico, ao preceptor, enfim, ao formador do profissional da saúde e incentivá-los; ouvi-los e descobrir neles seus desejos, suas dificuldades - parece simples, mas é um enorme desafio.

Outro desafio é pensar como podemos incluir o trabalho com inovações tecnológicas e pedagógicas, com o pouco que inovamos, na direção de chamar todos os protagonistas para o processo; em geral, chega-se dizendo como as coisas têm que ser feitas e pouco se escuta sobre como é a prática desse professor, e é essa a lógica que tentamos subverter.

Desafio também é incluir, obrigatoriamente, estratégias de compartilhamento na construção do processo de trabalho; em saúde, o espaço de educação permanente, por exemplo, é fundamental para isso acontecer; sentar junto para planejar o processo de trabalho, ter avaliações periódicas e, nessas ocasiões, pautar os processos de trabalho, abrindo oportunidade para o trabalho com as dificuldades, especialmente pelo fato de os grupos tutoriais constituírem-se de profissionais de diferentes áreas da saúde. Essa forma de se fazer a convocação, para que todos sintam-se protagonistas, responsabilizem-se pelo seu processo de trabalho, adquirindo governabilidade sobre ele, é que faz a diferença. 
Se pensarmos bem, qual o convite que fazemos, tanto para preceptores quanto para professores em um processo de formação pedagógica? Para trabalhar mais, para refletir mais, para realizar mais projetos pedagógicos, e isso dá trabalho. Mas esse trabalho, se for conjunto, revela uma potência imensurável e um interessante grau de criatividade, de intervenção, de interseção, de interpelação. Todos ganham, ampliam suas caixas de ferramentas ${ }^{2}$. Quem estava capturado, desanimado, achando que nada havia para fazer, com esse tipo de formação, vai produzir governabilidade e, aí, terá prazer, alegria.

Mas tudo isso vai depender de como se chega a essa conversa. Se eles (seja docente seja preceptor) estão no mundo do trabalho, se estão minimamente ali, se focamos isso, o trabalho deles, e não a formação deles, vamos identificar uma série de impasses, de problemas que cotidianamente os fazem sentirse desamparados. Porque esse caminho é solitário, particular, mas não pode ser desamparado. Então, se trazemos isso para discussão, eles ficam surpresos e se mostram disponíveis para o diálogo, para a troca de experiências. É preciso fazer desses momentos o tempo, por excelência, do diálogo, da livre expressão e da aposta de um consequente e contínuo comprometimento, com reflexos na conquista da autonomia.

2 Seriam três tipos de caixas de ferramentas: uma, vinculada à propedêutica e aos procedimentos (diagnósticos e terapêuticos), outra, aos saberes e outra, às relações trabalhador-usuário, cada uma delas expressando processos produtivos singulares implicados em certos tipos de produtos (Novo olhar sobre as tecnologias de saúde: uma necessidade contemporânea. Emerson Elias Merhy e Laura Camargo MacruzFeuerwerker, disponível em www.uff.br/ saudecoletiva/professores/merhy/capitulos-25.pdff). 
O curso cria esse espaço e esse tempo para problematizar os modos de ser e atuar na profissão. Ao longo do processo, surgem discussões sobre o "fazer" dos preceptores; inquietações são verbalizadas, debatidas, questionadas e revistas, proporcionando um movimento que possibilita a percepção da possibilidade de os alunos efetuarem mudanças que têm princípio no microuniverso de seus cenários de prática e podem culminar em propostas de intervenção, algumas delas até já implantadas (ROCHA, 2012).

Ainda, outro desafio é formar para o SUS, tema que sempre pareceu um tabu em discussões com os preceptores e professores. O SUS passa a ser uma discussão possível nesse processo de formação; considera-se o Sistema Único de Saúde uma produção de cada local, de cada grupo, uma área de tensionamento permanente, de instabilidade. É interessante perceber como à medida que o curso vai progredindo, esse tema ganha força e passa a ser objeto de estudo e se incorpora, aos poucos, ao discurso corrente dos preceptores como um ponto inflexível a ser obrigatoriamente incluído na prática da preceptoria. Fica claro que o aparecimento de novos problemas de saúde, relacionados às alterações ambientais e ao aparecimento de novas enfermidades, exige respostas diversificadas e sustentadas por um conhecimento sólido das ciências básicas, dos sistemas de saúde e de suas potencialidades.

É também interessante observar como, nesse processo de formação pedagógica da preceptoria, é comum encontrar essa questão de a pessoa seguir em frente diante da própria potência. E, aí, ela começa a discutir coisas que nunca discutiu 
e começa a se ver no mundo do trabalho de outra maneira, naquilo que potencializa o que ela muitas vezes faz de modo próprio e que ninguém nunca reconheceu, ações que, inclusive, tentam rotular como algo que não tem valor. Então, a experiência desse curso mostra muito essa possibilidade, de ganho indireto. É claro que, do ponto de vista do ganho direto, nesse processo de aprendizado, a pessoa instrumentalizase para as questões da prática no ensino, exercita, analisa e critica várias técnicas de ensino. Segundo Nóvoa (1992, p. 25), "a formação não se constrói por acumulação (de cursos, de conhecimentos ou de técnicas), mas, sim, através de uma reflexividade crítica sobre as práticas e de (re)construção permanente de uma identidade pessoal". Mas o que fica ressaltado é esse confronto com a questão da potência (e a consciência de que ela existe!), algo que vai além da instrumentalização didática.

Temos presenciado, entre os preceptores, uma conquista processual da função de autoria, à medida que eles vão se responsabilizando pela busca ativa da literatura para estudo dos problemas. Durante a formação, o que se espera é que eles sejam autores reais da própria produção. E, para isso, há uma série de dispositivos pedagógicos ${ }^{3}$ que podem ser acionados, tais como: problematizar os conceitos, instaurar a dúvida nas afirmações, tanto de formadores quanto dos alunos (professores e preceptores), e outras técnicas didáticas.

3 Entendemos como dispositivos pedagógicos um conjunto de materiais, ações e estratégias que podem ser eleitas para potencializar o processo de aprendizagem. Abrangem recursos como filmes, vinhetas, situações problemas, dramatização, a problematização de conceitos, portfólios, entre outros. 
Finaliza-se com a proposta de um projeto de intervenção com vistas a aplicar o uso de métodos ativos de aprendizagem nos diferentes ambientes de trabalho onde os cursistas encontramse inseridos. A apresentação do projeto como trabalho de conclusão do curso e o que temos recolhido ao longo das edições do curso com relação aos efeitos dessas implantações autoriza-nos a afirmar que essa análise preliminar revela o quanto esses profissionais se apropriam de conceitos e tendências pedagógicas - e literatura teórica em geral - no campo da educação. A ideia é inaugurar uma prática de produção teórica dos profissionais diretamente responsáveis pela formação prática dos estudantes de Medicina e de saúde, de modo geral, pelo cuidado e pelos procedimentos terapêuticos de pacientes dos hospitais universitários e de ensino das redes estadual e municipal.

Outro desafio é entender que, nas relações pedagógicas, haverá, sim, um desencontro, às vezes, insuportável, entre nós, formadores, e nosso público-alvo, seja de preceptores seja de professores. Esse desencontro não é um só, naquele momento, mas um processo para a vida. Afinal, cada um dos autores desse processo formativo chega trazendo seus saberes (produzidos com base na vivência e também a partir de distintas fontes, ainda mais num mundo em que a circulação de informações quebra inúmeras barreiras), desejos, entendimento do que é ensino, aprendizagem, dentre outras expectativas. É preciso suportar para não ficarmos capturados nisso; é preciso reconhecer esses desencontros e ter clareza sobre seus custos (conflitos, crises, atrasos) e benefícios (superações, rupturas, avanços). E, aí, quem está como facilitador desse processo precisa ter espaços de reflexão, de aprender que é assim 
mesmo, de ter escuta, porque, se não, não se consegue. É muito bonito dizer: trabalho com ruído, trabalho com tensão, mas trabalhar com esses desencontros não é fácil; é preciso ter pares para discutir e ter paciência. É um pouco o trabalho de formiga: usar ferramentas pequeninas, que não podem estar dissociadas de um projeto maior, e conversar o tempo inteiro. Na verdade, no trabalho que fazemos, e comprovamos no desenvolvimento dos projetos de intervenção, fica claro que vários trabalhos em nível micro, com um pouco de governabilidade, não fazem mudança institucional, mas fazem e produzem mudança na prática. Na formação, também. E mudanças significativas, especialmente nas relações de comunicação, de ensino e de aprendizagem dos preceptores com os internos e com os residentes, por exemplo.

Uma avaliação da prática dos preceptores egressos desses cursos deixa claro que eles assumiram um novo conceito de educação, rompendo padrões tradicionais de ensino, passando a atuar como protagonistas de mudanças que viabilizam um ensino médico - ou em outras áreas da saúde - inovador; revelaram apreensão de técnicas pedagógicas e capacidade de refletir criticamente sobre a própria prática de preceptoria, realizando transformações em seus ambientes laborais, validando esse curso como instrumento de educação permanente em saúde, viabilizando a formação pedagógica daqueles que são responsáveis pela educação em saúde na UFRJ, afirmando a importância de iniciativas como essa para outras instituições de ensino em saúde (ROCHA, 2012).

Mas é preciso lembrar que também temos uma grande área que fica totalmente inexplorada nesse processo de trabalho. 
Isso se dá no ensino de graduação também. Temos, por exemplo, os professores tradicionalmente formados e que acham que tudo que ensinam é relevante e, de outro lado, os alunos com seus currículos paralelos que são absolutamente desligados daquilo que é ensinado. Os dois lados não conversam entre si. Em alguns momentos, até conversam, mas só por meio de alguns professores que servem de ponte. Mas não é ponte que tem que ser feita. Os alunos fazem Ligas ${ }^{4}$, por exemplo, que são uma estratégia até meio messiânica, meio salvadora, a respeito das necessidades e dificuldades que eles encontram no percurso acadêmico. Os alunos entram para a Liga, relacionada a um tema e ficam completamente absorvidos, distanciados, porque o curso não deu e não dá isso a eles. Onde é que vamos fazer essa rede, aqui no meio, para isso funcionar? Como combater a racionalidade médica, tão arraigada, de grande parte dos docentes? É fazendo "furo no muro", não recuando, mostrando com o trabalho. Não é confortável. É preciso aprender a lidar com as ferramentas que fazem o furo. A caixa de ferramentas de Emerson Merhy (2000) ajuda a pensar, por exemplo, nos processos de inovação curricular. Qual caixa de ferramentas eu preciso usar para lidar

\footnotetext{
${ }^{4}$ As Ligas Acadêmicas são organizações formadas por um grupo de alunos com interesse comum, tendo um ou mais professores como coordenadores. Visam aprofundar os estudos em determinado tema da formação médica e em saúde. $O$ estímulo à produção científica e a realização de cursos de extensão também são atividades-fim de toda Liga Acadêmica e devem ser sempre estimuladas e promovidas pelos seus integrantes. Cabe às Ligas gerar outros cenários em que se exerça o ensino e a prática, sempre com atenção à demanda da população, ponto que deve nortear tanto a formação das Ligas quanto o seu foco de trabalho (Faculdade de Ciência Médicas da Facisa; Faculdade de Ciências Sociais e Aplicadas, Paraíba; e Faculdade de Medicina da Universidade Federal de Juiz de Fora).
} 
com os professores nesse processo formativo, para lidar com a linha de educação e saúde? Sem dúvida, precisamos usar as três tecnologias (leves, leves-duras e duras).

Em síntese, apontamos os desafios que são mais visíveis em nossa prática e que, ao serem enfrentados, vêm nos encaminhando para o fortalecimento do campo da educação e saúde na UFRJ.

São, então, os desafios:

- Atingir a pessoa e fazer com que ela identifique suas necessidades, suas dificuldades.

- Inserir os atuais professores nessa formação voltada para os princípios do SUS e para as novas tecnologias.

- A governabilidade - os preceptores, depois que passam pelo curso, descobrem que têm governabilidade, identificam seu papel no processo de trabalho e seu poder de governabilidade.

- O "furo do muro" - que esses processos formativos possam se dar com base nos processos de trabalho dos docentes, do público-alvo; não pode ser com uma agenda prefixada; os conteúdos, os módulos teóricos têm que ter como base o mundo do trabalho e a integração da universidade com os serviços de saúde. 
- Que os professores e preceptores entendam que não são uma ilha, que precisam estar em conexão com outras áreas de estudo. É preciso que eles comecem a se abrir para conexões que vão auxiliá-los na transformação do próprio trabalho.

Diante desses desafios, podemos pensar em possibilidades para superá-los:

As possibilidades são todas, pois não existe mundo em que tudo já esteja dominado. Se de fato quisermos colocar tudo isso em exercício, há muitas possibilidades de mudança, e em vários níveis. Talvez seja difícil acreditar, hoje em dia, em grandes revoluções, mas acreditamos nessas mudanças menores que, às vezes, têm mais potência transformativa que as grandes. Por exemplo: lideranças que se disponham a correr riscos e dar o exemplo, que exercitem a capacidade de argumentação, que acreditem no potencial do grupo para levar a cabo as mudanças e que não tenham medo de ousar, de se aventurar.

Mas é preciso ficar atento, pois também há uma potência que está nos alunos (todos); eles que nos transformam, indicam-nos caminhos. A força deles para tirar professores e preceptores da zona de conforto é enorme.

E, finalmente, o encontro que precisa ser compartilhado por todos. Para tanto, é nossa responsabilidade criar permanentemente oportunidades para que esse encontro aconteça. 


\section{REFERÊNCIAS}

BOTTI, S. H. O.; REGO, S. T. A. Docente-clínico: o complexo papel do preceptor na residência medica. PHYSIS Revista de Saúde Coletiva, Rio de Janeiro, v. 21, n. 1, p. 65-85, 2011.

BRASIL. Ministério da Saúde. Cadernos RH Saúde. Secretaria de Gestão do Trabalho e da Educação na Saúde - v. 3, n. 1, Brasília: Ministério da Saúde, 2006.

BRASIL. CONSELHO Nacional de Educação. Câmara De Educação Superior. Resolução CNE/CES № 4, de 7 de novembro de 2001. Institui Diretrizes Curriculares Nacionais do Curso de Graduação em Medicina.

BRASIL. Conselho Nacional de Educação. Câmara de Educação Superior. Resolução № 03, de 20 de junho de 2014. Institui Diretrizes Curriculares Nacionais do Curso de Graduação em Medicina e dá outras providências.

CECCIM, R. B.; FEUERWERKER, L. O quadrilátero da formação para a área da saúde: ensino, gestão, atenção e controle social. PHYSIS - Rev. Saúde Coletiva, v. 14, n. 1, p. 41-65, 2004.

CECCIM, R. B. Educação permanente em saúde: desafio ambicioso e necessário. Interface - Comunic., Saúde, Educ., v. 9, n. 16, p. 161-168, 2005.

CYRINO, E. G.; TORALLES-PEREIRA, M. L. Trabalhando com estratégias de ensino-aprendizado por descoberta na área da saúde: a problematização e a aprendizagem baseada em problema. Rio de Janeiro, Cad. Saúde Pública, v. 20, n. 3, p. 780-788, 2004. 
GARCIA, M. A. A. Saber, agir e educar: o ensinoaprendizagem em serviços de Saúde. Interface _Comunic, Saúde, Educ, v. 5, n. 8, p. 89-100, 2001.

LARROSA, J. B. Notas sobre a experiência e o saber de experiência. Revista Brasileira de Educação, n. 19, 2002.

MERHY, E. E. Um ensaio sobre o médico e suas valises tecnológicas. Contribuições para compreender as reestruturações produtivas do setor Saúde. Interface _ Comunic, Saúde, Educ. (Botucatu), v. 4, n. 6, 2000.

NÓVOA, A. Formação de professores e profissão docente. In: A. Nóvoa (coord.) Os professores e a sua formação. Lisboa: Publicações Dom Quixote/Instituto de Inovação Educacional, 1992. p. 13-33.

RIBEIRO, V. M. B. (organizadora). Formação pedagógica de preceptores do ensino em saúde. Juiz de Fora: Ed. UFJF; 2011.

ROCHA, H. C. Avaliação da prática de preceptoria após formação pedagógica. 2012. 106 f. Dissertação (Mestrado em Educação em Ciências e Saúde) - Núcleo de Tecnologia Educacional para a Saúde, UFRJ, 2012.

\section{ABSTRACT}

Experience report on the development of a blended learning model course offered by the Federal University of Rio de Janeiro: "Health Professionals' Trainers' Teaching Training: a preceptorship of medical internship in question". Aiming at a better qualification of medical training and the implementation of an active pedagogical strategy used with health professionals' trainers for SUS, the course uses Problem 
Based Learning (PBL) as a method, and the support of a virtual platform of its own. Participants evaluated the use of this interactive method as more effective, because the strategies of active research, group work and discussions in online forums were particularly motivating for the acquisition of skills required to study and answer the leading questions during the learning process provided by the four modules of the course as well for making changes in their practices.

Keywords: Education. Problem based learning. Health.

\section{Victoria Maria Brant Ribeiro}

Professora associada e pesquisadora do Programa de Pesquisa em Tuberculose e do Programa de Pós-Graduação em Clínica Médica da Universidade Federal do Rio de Janeiro (UFRJ).

victoria.brantr@gmail.com

\section{Elizabeth Menezes Teixeira Leher}

Psicóloga graduada pela UFRJ (1982), especialista em Educação e Saúde (1988), mestre em Educação (1995) pela UFRJ e doutora em Educação (2002) pela Universidade de São Paulo (USP). Especialista em Ativação de Mudanças na Formação Superior de Profissionais de Saúde - ENSP/Fiocruz (2013/2014). Aposentada pela UFRJ, desenvolveu atividades no Núcleo de Tecnologia Educacional para a Saúde (1983-2014), integrando a equipe responsável pelo Curso de Aperfeiçoamento Formação Pedagógica de Preceptores do Ensino em Saúde (2007-2014). 
Pesquisadora do grupo de pesquisa Educação e ComunicaçãoPPGE da Universidade Estadual do Rio de Janeiro (UERJ), desde 2003. Pesquisadora especialista visitante em Tecnologias Educacionais na Escola Politécnica de Saúde Joaquim Venâncio/ Fiocruz - Bolsista especialista visitante máster - Fiocruz/CNPq (março 2015-atual).

eleher@gmail.com

\section{Maria Paula Cerqueira Gomes}

Psicóloga, professora associada do Instituto de Psiquiatria (IPUB) da UFRJ. Mestre em Saúde Coletiva pelo Instituto Moreira Sales (IMS) da UERJ e doutora em Saúde Mental pelo IPUB-UFRJ. Pesquisadora na linha Micropolítica do Trabalho e o Cuidado em Saúde (UFRJ). Coordenadora da Residência Multiprofissional de Saúde Mental Ipub-UFRJ.

paulacerqueiraufrj@gmail.com

\section{Hulda Cristina Rocha}

Médica formada pela UERJ (1979-1984), com residência médica em Anestesiologia pelo Hospital Clementino Fraga Filho da UFRJ (1985-1987) e mestrado em Educação em Saúde pelo Núcleo de Tecnologia Educacional para Saúde, da UFRJ (2011-2012). Cursou Formação Pedagógica de Preceptores para Área da Saúde da UFRJ (2010) e Formação de Tutores na especialização do curso de Docência na Saúde na UFRGS/ EaD (2014). Tutora do Curso de Formação Pedagógica para Preceptores da Área da Saúde da UFRJ (2012) e do Curso Docência na Saúde UFRGS (2014-2015).

huldacristina@gmail.com 


\section{Denise da Silva Mattos}

Médica do Departamento de Medicina de Família e Comunidade da Faculdade de Medicina (FM) da UFRJ. Mestre em Clinica Médica pela UFRJ; coordenadora adjunta do Programa Curricular Integrado Atenção Integral à Saúde da FM-UFRJ; tutora do curso de Formação de Preceptores da UFRJ.

\section{Mirian Vieira Maia}

Médica Anestesiologista do Hospital Universitário Clementino Fraga Filho, da UFRJ, e do Hospital Universitário Pedro Ernesto, da UERJ. Mestre em Educação em Ciências e Saúde pelo Núcleo de Tecnologia Educacional para a Saúde (Nutes), da UFRJ. Tutora do curso de Formação Pedagógica de Preceptores da UFRJ.

\section{Valéria Ferreira Romano}

Professora adjunta da Faculdadede Medicina da UFRJ; médica da família, doutora em Saúde Coletiva pelo Instituto de Medicina Social da UERJ; coordenadora do Laboratório de Ensino em Atenção Primária (Leap), da UFRJ; membro do Colegiado de Coordenação da Residência em Medicina de Família e Comunidade da UFRJ; docente permanente do Mestrado em Atenção Primária da UFRJ.

valromano@uol.com.br 